Proceedings

\title{
Detection of Ammonia Based on Stimuli-Responsive Hydrogels ${ }^{+}$
}

\author{
Jan Erfkamp *, Margarita Guenther and Gerald Gerlach \\ Solid-State Electronics Laboratory, Technische Universität Dresden, 01069 Dresden, Germany; \\ mguenthe@mail.zih.tu-dresden.de (M.G.); gerald.gerlach@tu-dresden.de (G.G.) \\ * Correspondence: jan.erfkamp@tu-dresden.de; Tel.: +49-351-463-43793 \\ † Presented at the Eurosensors 2018 Conference, Graz, Austria, 9-12 September 2018. \\ Published: 7 December 2018
}

\begin{abstract}
This article describes an ammonia-responsive hydrogel based on acrylic acid (AAc) and 2-(dimethylamino)ethyl methacrylate (DMAEMA). The influence of the hydrogel composition on swelling behavior in the alkaline range was shown. Furthermore, the hydrogel swelling in ammonia solutions was tested and a detection limit in the range of $1 \mathrm{mmol} / \mathrm{L}$ ammonia in dependence of the buffer solution was determined.
\end{abstract}

Keywords: stimuli-responsive hydrogel; ammonia; $\mathrm{pH}$ value; alkaline $\mathrm{pH}$ conditions; chemical sensor

\section{Introduction}

Ammonia $\left(\mathrm{NH}_{3}\right)$ is one of the most important inorganic compounds in chemical engineering. In 2011, 140 megatons of ammonia were produced worldwide based on the Haber-Bosch process [1]. Ammonia is one of the key compounds for the production of fertilizers, pharmaceuticals, dyes or disintegrates [2]. However, too high ammonia concentrations could be a serious health threat [3]. Therefore, it is necessary to monitor ammonia as part of ambient conditions in environmental analytics [4] or to measure the atmospheric pollution from automobiles [5]. Furthermore, ammonia could be an indicator for medical diseases like stomach ulcers due to bacterial infections [6] or a disturbed urea balance due to a kidney disorder [7]. According to the German Drinking Water Regulations from 2001, the limit value of dissolved ammonium ions in drinking water is $0.5 \mathrm{mg} / \mathrm{L}$ [8]. Depending on the application, it is necessary to detect ammonia in different concentration ranges [3].

In aqueous solution, ammonia reacts as a base $\left(\mathrm{pK}_{\mathrm{B}}=4.75\right)$ to ammonium and hydroxide ions according to the following reaction equation [9]:

$$
\mathrm{NH}_{3}+\mathrm{H}_{2} \mathrm{O} \rightarrow \mathrm{NH}_{4}^{+}+\mathrm{OH}^{-}
$$

The result is a change in $\mathrm{pH}$ value, which can be detected via $\mathrm{pH}$-responsive hydrogels. Hydrogels are three-dimensional polymer networks, which can absorb a huge amount of water. Due to the chemical modification by using different monomers, these gels have various swelling properties depending on different stimuli like salt concentrations, temperature or $\mathrm{pH}$ [10]. In this work, we present a pH-sensitive hydrogel based on acrylic acid (AAc) and 2-(dimethylamino)ethyl methacrylate (DMAEMA), which can be used for the detection of ammonia. These gels can be combined with piezoresistive pressure sensors, which can transform the swelling pressure into a measurable output voltage [11]. For example, hydrogel-based piezoresistive sensors have been used so far for the detection of the $\mathrm{pH}$ value [12], temperature [13], biomolecules like glucose [14] or organic solvents like ethanol [15]. 


\section{Materials and Methods}

\subsection{Synthesis of pH-Sensitive Poly Acrylic Acid-co-Dimethylaminoethyl Methacrylate Hydrogels}

For the detection of ammonia, a pH-sensitive hydrogel based on acrylic acid (AAc) and dimethylaminoethyl methacrylate (DMAEMA) was synthesized. Thereby, hydrogel with different contents of AAc (x mol \%, Sigma Aldrich, St. Louis, MO, USA) and DMAEMA (100-x mol \%, Sigma Aldrich, St. Louis, MO, USA) were combined with $1 \mathrm{~mol} \%$ of the crosslinker bisacrylamide (Carl Roth, Karlsruhe, Germany). In all cases, the total concentration of AAc and DMAEMA was $1.6 \mathrm{~mol} / \mathrm{L}$ [16]. After degassing the pregel solution with nitrogen for $5 \mathrm{~min}$, the polymerization was initiated with $1 \mathrm{~mol} \%$ ammonium peroxodisulfate (Sigma Aldrich, St. Louis, MO, USA) and $1 \mathrm{~mol} \% \mathrm{~N}, N_{,} N^{\prime}, N^{\prime}-$ tetramethylethylenediamine (Carl Roth, Karlsruhe, Germany). The total volume of a synthesis approach was $600 \mu \mathrm{L}$. The pregel solution was filled in a vial shell (1 mL, VWR, Radnor, PA, USA) and polymerized overnight in an oven at $35^{\circ} \mathrm{C}$. After polymerization, vial shells were carefully smashed without damaging the hydrogel. One tablet of a phosphate-buffered saline (PBS, pH 7.4, I = $0.15 \mathrm{~mol} / \mathrm{L}$, Sigma Aldrich, St. Louis, MO, USA) was dissolved in $200 \mathrm{~mL}$ distilled water. The gels were cut in small pieces with a thickness of about $5 \mathrm{~mm}$ and were washed in PBS buffer, $\mathrm{pH}$ 7.4, for 3 days to remove unreacted monomers.

\subsection{Swelling Studies at Different $p H$ Values}

After washing, the gels were conditioned fivefold in PBS solutions ( $\mathrm{pH} 7.4 \leftrightarrows \mathrm{pH} 10$ ). The $\mathrm{pH}$ values were adjusted by a sodium hydroxide solution $(0.1 \mathrm{~mol} / \mathrm{L})$ using a $\mathrm{pH}$ meter. Subsequently, the gels were washed in PBS buffer, $\mathrm{pH}$ 7.4, and the initial mass of the hydrogel $m_{0}$ was measured. After incubating in a PBS buffer with a defined $\mathrm{pH}$ value for overall $24 \mathrm{~h}$, whereby the buffer changed five times every $1-2 \mathrm{~h}$ to wash the gel, the hydrogel mass $m$ after swelling and the $\mathrm{pH}$ value of the solution were detected. In the following measurements, the gels were incubated in a new PBS buffer with another $\mathrm{pH}$ values. The swelling degree $S$ was calculated with the following formula:

$$
S=\left(m-m_{0}\right) / m_{0}
$$

\subsection{Swelling Studies at Different Ammonia Concentrations}

Swelling studies were performed in PBS buffer and in an isotonic saline solution $(\mathrm{NaCl}, 9 \mathrm{~g} / \mathrm{L}$, $\mathrm{I}=0.15 \mathrm{~mol} / \mathrm{L})$. After washing and conditioning, the initial mass of the hydrogel $m_{0}$ and the $\mathrm{pH}$ value were measured in $\mathrm{PBS}$ or $\mathrm{NaCl}$ solution without $\mathrm{NH}_{3}$. Ammonium hydroxide $(\sim 1 \mathrm{~mol} / \mathrm{L}$ ammonia in water, Sigma Aldrich, St. Louis, MO, USA) was used to prepare a $1 \mathrm{~mol} / \mathrm{L}$ ammonia stock solution in PBS and $\mathrm{NaCl}$ buffer. A solution with a defined $\mathrm{NH}_{3}$ concentration was prepared with the stock solution and the gels were incubated for $24 \mathrm{~h}$. After determination of the hydrogel mass $m$, the $\mathrm{pH}$ value and the swelling degree $S(1)$, the hydrogels were placed in a solution with another ammonia concentration for $24 \mathrm{~h}$.

\section{Results and Discussion}

The swelling degree of poly(AAc-co-DMAEMA) hydrogels in dependence on the $\mathrm{pH}$ value for different monomer contents is shown in Figure 1a.

Hydrogels having compositions of 50-70 mol \% AAc and 30-50 mol \% DMAEMA were successfully synthesized. For hydrogels with more than $70 \mathrm{~mol} \%$ AAc, no complete polymerization was observed under the described conditions. Furthermore, hydrogels with more than $50 \mathrm{~mol} \%$ DMAEMA could not be utilized under mechanical stress.

Hydrogels based on polyAAc swell under basic conditions because of the deprotonation of the carboxyl group and, thus, an increase of the electrostatic repulsion of the carboxylate anions in the gel [17]. In literature, the $\mathrm{pK}$ A value of polyAAc was determined from 5.35 to 7.2 [18]. As a result, the deprotonation should be in a more acidic range. Through the basic monomer DMAEMA (pks $=7.8[10])$, the operation range of the gel was shifted towards a more alkaline range [16]. 
The higher the content of DMAEMA is, the higher becomes the swelling degree of the hydrogels. However, the polymer system with the highest swelling degree shows a non-linear swelling behavior. Hydrogels with $60 \mathrm{~mol} \%$ AAc and $40 \mathrm{~mol} \%$ DMAEMA were used in the following experiments because these gels have a linear swelling behavior over a large $\mathrm{pH}$ range and show a high sensitivity.

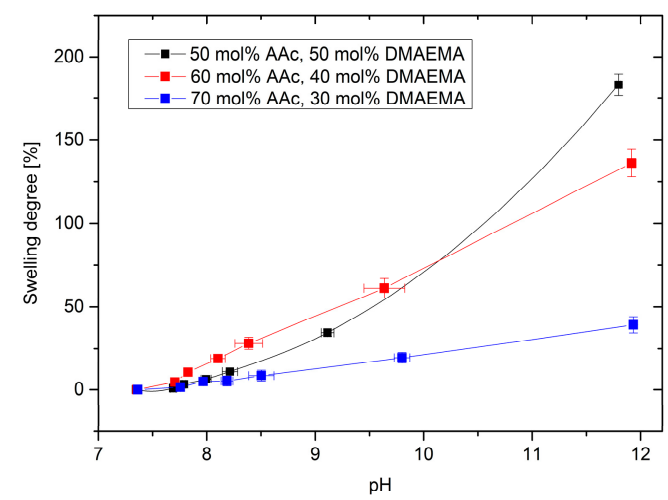

(a)

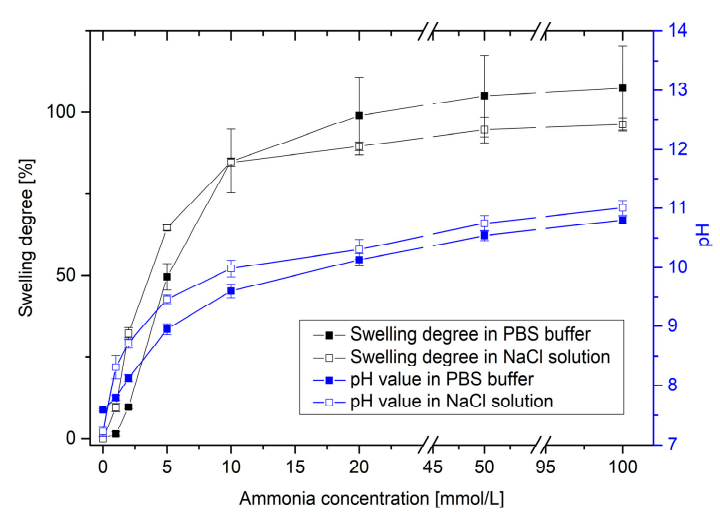

(b)

Figure 1. Results of the swelling studies: (a) Swelling degree of poly (AAc-co-DMAEMA) hydrogels versus $\mathrm{pH}$ value for different monomer contents in PBS buffer; (b) Swelling behavior of poly(AAc-coDMAEMA) (60\% AAc, 40\% DMAEMA) hydrogels and resulting $\mathrm{pH}$ value for different ammonia concentrations in PBS buffer and isotonic saline solutions $(\mathrm{NaCl})$.

Figure $1 \mathrm{~b}$ shows the swelling of poly(AAc-co-DMAEMA) hydrogels at different ammonia concentrations in PBS buffer and in an isotonic saline solution. With increasing the ammonia concentration, the $\mathrm{pH}$ value of the solution increases significantly. This results in a swelling of the $\mathrm{pH}$-sensitive hydrogel. Even small concentrations can be detected via swelling of the hydrogel. It was possible to detect small changes in $\mathrm{pH}$ value via hydrogel swelling. With this polymer system, it was also possible to detect small concentrations of ammonia. Furthermore, a difference in the detection limit between PBS solution and isotonic saline solution could be observed. PBS buffer should keep the $\mathrm{pH}$ value in the physiological range as constant as possible. Through the phosphate buffer, small changes in $\mathrm{pH}$ value can be compensated in solution. With changing the ammonia concentration from $0 \mathrm{mmol} / \mathrm{L}$ to $1 \mathrm{mmol} / \mathrm{L} \mathrm{NH}_{3}$, the $\mathrm{pH}$ value increased only from $\mathrm{pH} 7.59$ to $\mathrm{pH} 7.79(\Delta \mathrm{pH}=0.20)$ in PBS buffer. However, in an isotonic saline solution, the $\mathrm{pH}$ value increased from $\mathrm{pH} 7.23$ to $\mathrm{pH} 8.31$ $(\Delta \mathrm{pH}=1.08)$. As a result, a significant swelling of the hydrogels could be detected only in sodium chloride solution. The corresponding detection limit amounts to ca. $1 \mathrm{mmol} / \mathrm{L} \mathrm{NH}$. In PBS buffer, a substantial swelling of the hydrogels was observed of concentrations of more than $2 \mathrm{mmol} / \mathrm{L} \mathrm{NH}_{3}$. At higher ammonia concentrations, no relevant difference between the buffer solutions could be seen.

\section{Conclusions}

Based on poly(AAc-co-DMAEMA) hydrogels, it was possible to detect ammonia in solutions within the low millimolar range. The detection limit depends on the used buffer solution and could be less than $1 \mathrm{mmol} / \mathrm{L} \mathrm{NH}_{3}$. This hydrogel system can be used especially for the detection of low concentrations of ammonia between $1 \mathrm{mmol} / \mathrm{L}$ and $20 \mathrm{mmol} / \mathrm{L}$, which is of particular interest for applications in environmental or biomedical analysis.

Author Contributions: J.E., M.G. and G.G. conceived and designed the experiments; J.E. performed the experiments; J.E. analyzed the data; J.E. wrote the paper.

Acknowledgments: This work is a result of the Research Training Group “Hydrogel-based microsystems" (GRK 1865) funded by the "Deutsche Forschungsgemeinschaft" (DFG).

Conflicts of Interest: The authors declare no conflict of interest. 


\section{References}

1. Milton, R.D.; Cai, R.; Abdellaoui, S.; Leech, D.; De Lacey, A.L.; Pita, M.; Minteer, S.D. Bioelectrochemical Haber-Bosch Process: An Ammonia-Producing $\mathrm{H}_{2} / \mathrm{N}_{2}$ Fuel Cell. Angew. Chem. Int. Ed. 2017, 56, 2680-2683, doi:10.1002/anie.201612500.

2. Schlögl, R. Katalytische Ammoniaksynthese - eine "unendliche Geschichte"? Angew. Chem. 2003, 115, 20502055, doi:10.1002/ange.200301553.

3. Timmer, B.; Olthuis, W.; van den Berg, A. Ammonia sensors and their applications-A review. Sens. Actuators B Chem. 2005, 107, 666-677, doi:10.1016/j.snb.2004.11.054.

4. Erisman, J.W.; Otjes, R.; Hensen, A.; Jongejan, P.; van den Bulk, P.; Khlystov, A.; Möls, H.; Slanina, S. Instrument development and application in studies and monitoring of ambient ammonia. Atmos. Environ. 2001, 35, 1913-1922, doi:10.1016/S1352-2310(00)00544-6.

5. Durbin, T.D.; Wilson, R.D.; Norbeck, J.M.; Miller, J.W.; Huai, T.; Rhee, S.H. Estimates of the emission rates of ammonia from light-duty vehicles using standard chassis dynamometer test cycles. Atmos. Environ. 2002, 36, 1475-1482, doi:10.1016/S1352-2310(01)00583-0.

6. Kearney, D.J.; Hubbard, T.; Putnam, D. Breath Ammonia Measurement in Helicobacter pylori Infection. Dig. Dis. Sci. 2002, 47, 2523-2530, doi:10.1023/A:1020568227868.

7. Narasimhan, L.R.; Goodman, W.; Patel, C.K.N. Correlation of breath ammonia with blood urea nitrogen and creatinine during hemodialysis. Proc. Natl. Acad. Sci. USA 2001, 98, 4617-4621, doi:10.1073/pnas.071057598.

8. Verordnung über die Qualität von Wasser für den menschlichen Gebrauch (TrinkwasserverordnungTrinkwV 2001). Available online: https://www.gesetze-im-internet.de/trinkwv_2001/TrinkwV_2001.pdf (accessed on 6 June 2018).

9. Çaglar, P.; Narayanaswamy, R. Ammonia-sensitive fibre optic probe utilising an immobilised spectrophotometric indicator. Analyst 1987, 112, 1285-1288, doi:10.1039/AN9871201285.

10. Guenther, M.; Wallmersperger, T.; Gerlach, G. Piezoresistive Chemical Sensors Based on Functionalized Hydrogels. Chemosensors 2014, 2, 145-170, doi:10.3390/chemosensors2020145.

11. Guenther, M.; Gerlach, G. Hydrogels for Chemical Sensors. In Hydrogel Sensors and Actuators: Engineering and Technology; Gerlach, G., Arndt, K.-F., Eds.; Springer: Berlin, Heidelberg, 2010; pp. 165-195 ISBN 978-3540-75645-3.

12. Trinh, Q.T.; Gerlach, G.; Sorber, J.; Arndt, K.-F. Hydrogel-based piezoresistive pH sensors: Design, simulation and output characteristics. Sens. Actuators B Chem. 2006, 117, 17-26, doi:10.1016/j.snb.2005.10.041.

13. Franke, D.; Binder, S.; Gerlach, G. Performance of Fast-Responsive, Porous Crosslinked Poly(NIsopropylacrylamide) in a Piezoresistive Microsensor. IEEE Sens. Lett. 2017, 1, 1-4, doi:10.1109/LSENS.2017.2773626.

14. Schmidt, U.; Jorsch, C.; Guenther, M.; Gerlach, G. Biochemical piezoresistive sensors based on hydrogels for biotechnology and medical applications. J. Sens. Sens. Syst. 2016, 5, 409-417, doi:10.5194/jsss-5-409-2016.

15. Erfkamp, J.; Guenther, M.; Gerlach, G. Hydrogel-based piezoresistive sensor for the detection of ethanol. J. Sens. Sens. Syst. 2018, 7, 219-226, doi:10.5194/jsss-7-219-2018.

16. Zhai, M.; Chen, Y.; Yi, M.; Ha, H. Swelling behaviour of a new kind of polyampholyte hydrogel composed of dimethylaminoethyl methacrylate and acrylic acid. Polym. Int. 2004, 53, 33-36, doi:10.1002/pi.1413.

17. Turan, E.; Çaykara, T. Swelling and network parameters of $\mathrm{pH}$-sensitive poly(acrylamide-co-acrylic acid) hydrogels. J. Appl. Polym. Sci. 2007, 106, 2000-2007, doi:10.1002/app.26848.

18. Park, H.; Robinson, J.R. Mechanisms of Mucoadhesion of Poly(acrylic Acid) Hydrogels. Pharm. Res. 1987, 4, 457-464, doi:10.1023/A:1016467219657.

(C) 2018 by the authors. Licensee MDPI, Basel, Switzerland. This article is an open access article distributed under the terms and conditions of the Creative Commons Attribution (CC BY) license (http://creativecommons.org/licenses/by/4.0/). 